\title{
SOIL SCIENCE SOCIETY OF AMERICA JOURNAL
}

\section{Soil Water Regime in Space and Time in a Small Georgia Piedmont Catchment under Pasture}

\author{
D. M. Endale,* D. S. Fisher, and H. H. Schomberg
}

\begin{abstract}
Soil water influences hydrological, biological, and biogeochemical processes that determine on- and off-site response of landscapes under different agricultural uses. There are relatively little detailed spatial and temporal soil water measurements to validate current representations of spatial and temporal soil water variability. Soil water was measured over 3 yr at 12 sites to a 1.2-m depth in a 7.8-ha pasture catchment in the Georgia Piedmont in southeastern USA. The Mahalanobis statistical difference was estimated between all pairs of measurement sites for soil water. Multidimensional scaling of the Mahalanobis differences showed that only a single statistical dimension was separating the observed soil water variations at measurement sites $(r=0.99)$. This statistical dimension was then found to be most closely correlated with the depth to the Bt and the depth of the Ap horizons for explaining the observed variation in soil water between sampling sites $(r=0.69$ and $r=0.8$, respectively). Those sites where the Bt, an argillic horizon, was close to the surface, even when higher up the landscape, were generally wetter than those in which the $B t$ was deeper, even in the lower part of the landscape. The depth to the Bt horizon may serve as an indicator of the portions of the watershed most likely to be primary sources of runoff in association with the depth of overlying coarse-textured soil. Volumetric soil water content was generally greatest in winter (22 to $30 \%$ average) and least in summer ( 8 to $12 \%$ except when influenced by intense summer storms). To fully understand the soil water dynamics of Piedmont or similar landscapes, it is important to know the spatial distribution of the depth to the Bt horizon. Improved understanding of the soil water dynamics could lead to improved land use decisions, erosion control, and management of water resources. This should be of interest to many researchers across many disciplines.
\end{abstract}

U NDERSTANDING the spatial and temporal characteristics of soil water across landscapes is important for evaluation of the influence of agricultural land use on water resources. Interactions among landscape and

D.M. Endale, D.S. Fisher, and H.H. Schomberg, USDA-ARS, J. Phil Campbell Sr. Natural Resource Conservation Center, 1420 Experiment Station Road, Watkinsville, GA 30677. Received 4 Apr. 2005. *Corresponding author (dendale@uga.edu).

Published in Soil Sci. Soc. Am. J. 70:1-13 (2006).

Soil Physics and Soil \& Water Management \& Conservation doi:10.2136/sssaj2005.0106

(c) Soil Science Society of America

677 S. Segoe Rd., Madison, WI 53711 USA soil water are apparent in the partitioning of precipitation to surface and subsurface water, plant water availability, heat and energy exchange between land surface and the atmosphere, and fate and transport of chemical and biological soil constituents (Loague, 1992; Western et al., 1998; Robock et al., 2000).

Soil water varies spatially and temporally because of differences in soil properties, vegetation, topography, weather, and land use. Historically, relatively few detailed spatial and temporal soil water measurements have been made. As a result, spatial variability has been estimated using geostatistical techniques, deterministic models, and from remote sensing methods (O'Loughlin, 1986; Western et al., 1999a). Water balance models of different complexities have also been adapted for spatial representations. Validating the applicability of these approaches has been hindered by lack of suitable soil water data.

Environmental problems have created a demand for reliable agro-hydrologic models (Beven, 1989; Grayson et al., 1992; Western et al., 1999a) that require testing with extensive datasets. According to the National Research Council (NRC, 1999), site-specific research and models will always be necessary for watershed management because regional variation in physical hydrology, ecology, and human impacts significantly affect the functioning of watersheds. Weiler and McDonnell (2004) make the point that simply observing outflow from a catchment is a weak test of a model or process conceptualization.

The objective of this research was to determine the variation of soil water by seasons and landscape position while testing for mechanisms that might explain the variation observed in a small pastured ( $28 \mathrm{yr})$ catchment in the Georgia Piedmont of southeastern USA. The Georgia Piedmont is part of the 16.7 million ha (41 million acres) Southern Piedmont region. The Southern Piedmont is approximately 100 to $300 \mathrm{~km}$ wide, immediately east of the Appalachian Mountains, and extends from Alabama to Virginia (Radcliffe and West, 2000). Pastures have reduced acute problems of erosion as they gradually replaced

Abbreviations: MD, Mahalanobis distance; MDS, multidimensional scaling; TDR, time domain reflectometry. 
row-cropped agricultural fields in the Piedmont since the 1950 s as a result of poor economics for the cropping systems and the lower capital investment of grazing systems.

\section{MATERIALS AND METHODS}

\section{Experimental Site, Soil, and Land Use}

The experimental site was a 7.8-ha catchment, designated as W1, at the USDA-ARS, J. Phil Campbell Sr. Natural Resource
Conservation Center, Watkinsville, GA ( $33^{\circ} 54^{\prime} \mathrm{N}$ and $\left.83^{\circ} 24^{\prime} \mathrm{W}\right)$ within the Georgia Piedmont. The topography, soils and land use history of W1 are typical of many sloping fields throughout the Southern Piedmont. The small catchment is pear shaped along an east-west axis about $383 \mathrm{~m}$ long with a 16-m elevation drop ( $4.2 \%$ slope; Fig. 1). The middle part is flatter with 3 to $4 \%$ slope. This is surrounded by 4 to $8 \%$ slope zones in a horseshoe fashion.

Moderately eroded Cecil and Pacolet soils (fine, kaolinitic, thermic Typic Kanhapludults) occupy about 69 and 31\% of

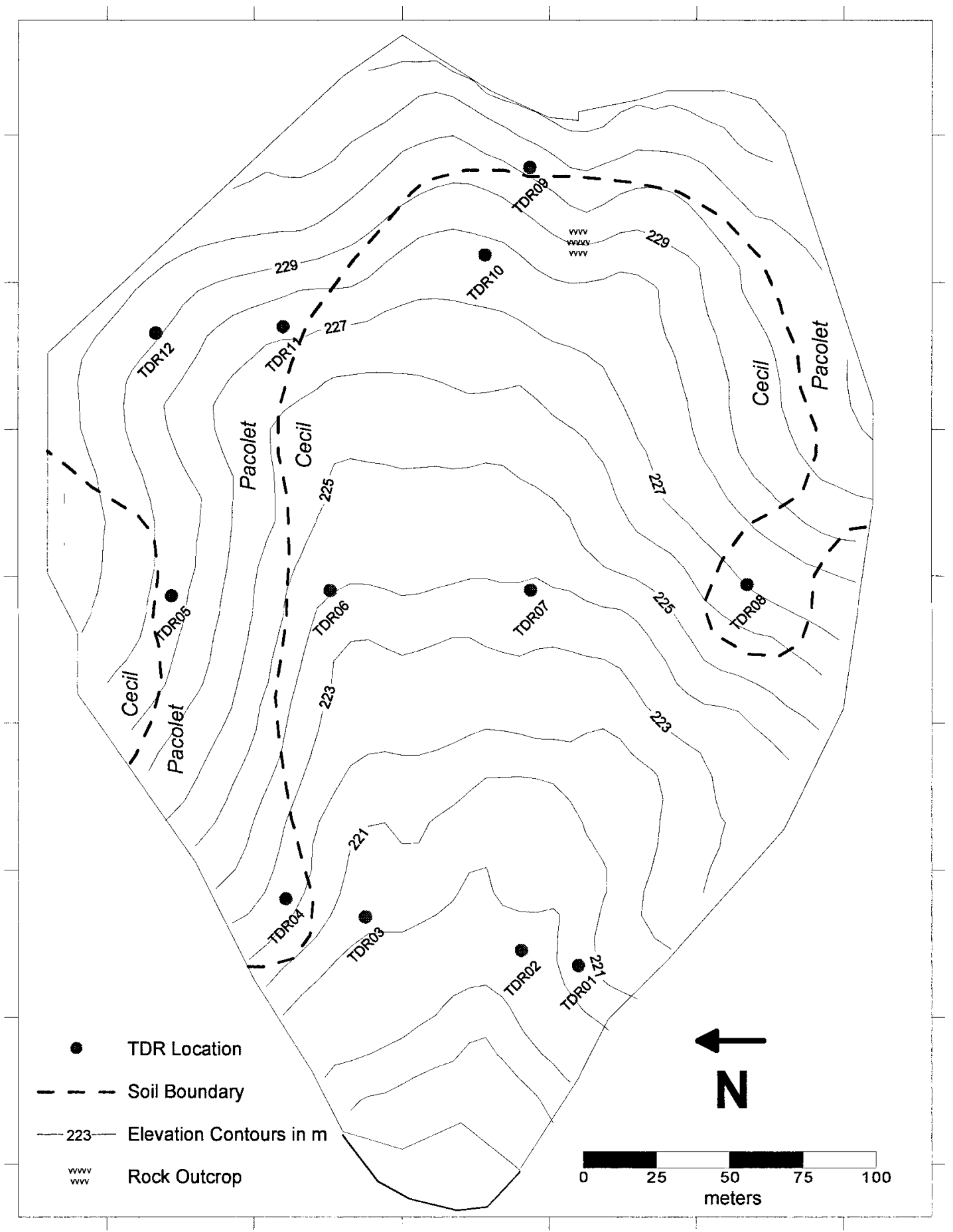

Fig. 1. Elevation contour lines in meters, soil boundary, and location of time domain reflectometry (TDR)-based soil water content measurement sites at W1. 
W1, respectively (Fig. 1). Cecil and related soils are mapped in over $50 \%$ of the Southern Piedmont (Radcliffe and West, 2000). The Pacolet soils have less depth than those of the Cecil series but the properties of the two soils are similar otherwise.

The soils generally have brownish-gray sandy loam to red clay loam surface horizons overlaying red clayey argillic horizons. Mean percentages of clay, sand, and silt content by depth are presented in Fig. 2a. Clay content variations by depth at two sites close to each of six of twelve time domain reflectometry (TDR)-based soil water content measurement sites are shown in Fig. 2b. These figures were produced from textural and horizon differentiation data collected at 52 locations in W1 on an approximately 30 by $30 \mathrm{~m}$ grid (R.R Bruce, Soil Scientist, Retired, USDA-ARS, Watkinsville, GA, personal communication, 2004). These same data were used to produce contour line map of the depth to the top of the Bt horizon (Fig. 3) from grid files generated using the kriging option in
SURFER Version 6 (Golden Software, Inc., Golden, CO). The Bt horizon at $\mathrm{W} 1$ begins $<35 \mathrm{~cm}$ from the surface in the Pacolet, but is 35 to $65 \mathrm{~cm}$ or deeper from the surface in the Cecil.

The subsoil in both soils is underlain by several meters thick $\mathrm{C}$ horizon of porous decomposed rock material (saprolite) resting on solid rock typically ranging from 5 to $20 \mathrm{~m}$ below the surface. Rock outcrops are visible at two locations (Fig. 1). However, drilling for a monitoring well and four piezometers evenly spaced in W1 did not encounter hard rock at depths $<$ $9 \mathrm{~m}(<30 \mathrm{ft})$.

Saturated hydraulic conductivity $\left(K_{\mathrm{s}}\right)$ varies among Cecil, Pacolet, and related soil horizons, and generally is highest in the Ap and BA horizons and least near the bottom of the $\mathrm{Bt}$ and top of the BC or CB horizons (Radcliffe and West, 2000). Bruce et al. (1983) measured $K_{\mathrm{s}}$ values of about 14 to $20+\mathrm{cm}$ $\mathrm{h}^{-1}$ in the Ap horizon falling to $10^{-2}$ to $10^{-3} \mathrm{~cm} \mathrm{~h}^{-1}$ in the lower
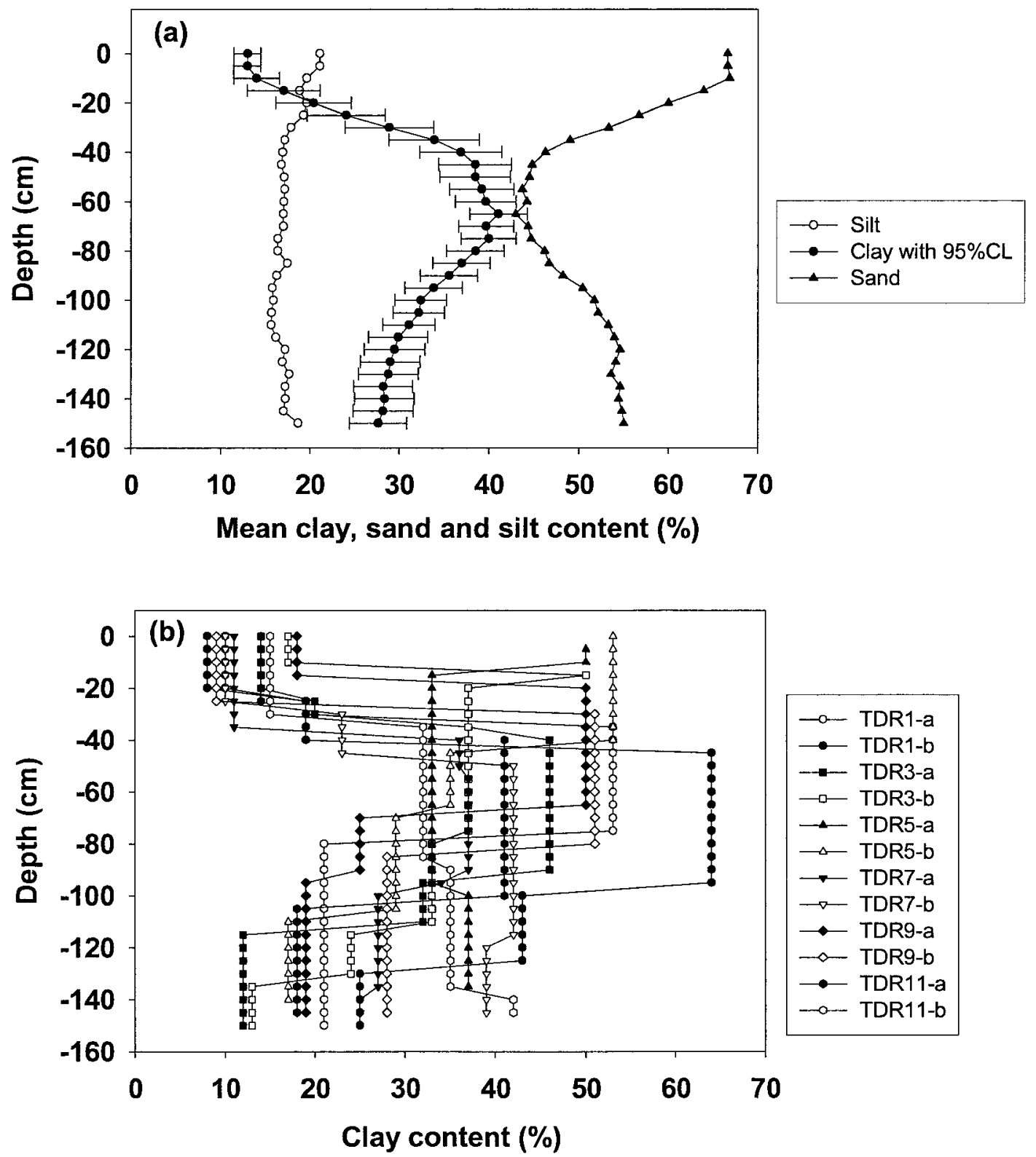

Fig. 2. Textural differentiation with depth at W1: (a) mean clay, sand, and silt content with $95 \%$ confidence limit $(95 \%$ CL) for mean clay content; and (b) spatial variation of clay content with depth. TDR1-a, TDR1-b, etc., indicate data from two locations (a and b) near the corresponding time domain reflectometry-based measurement site. 


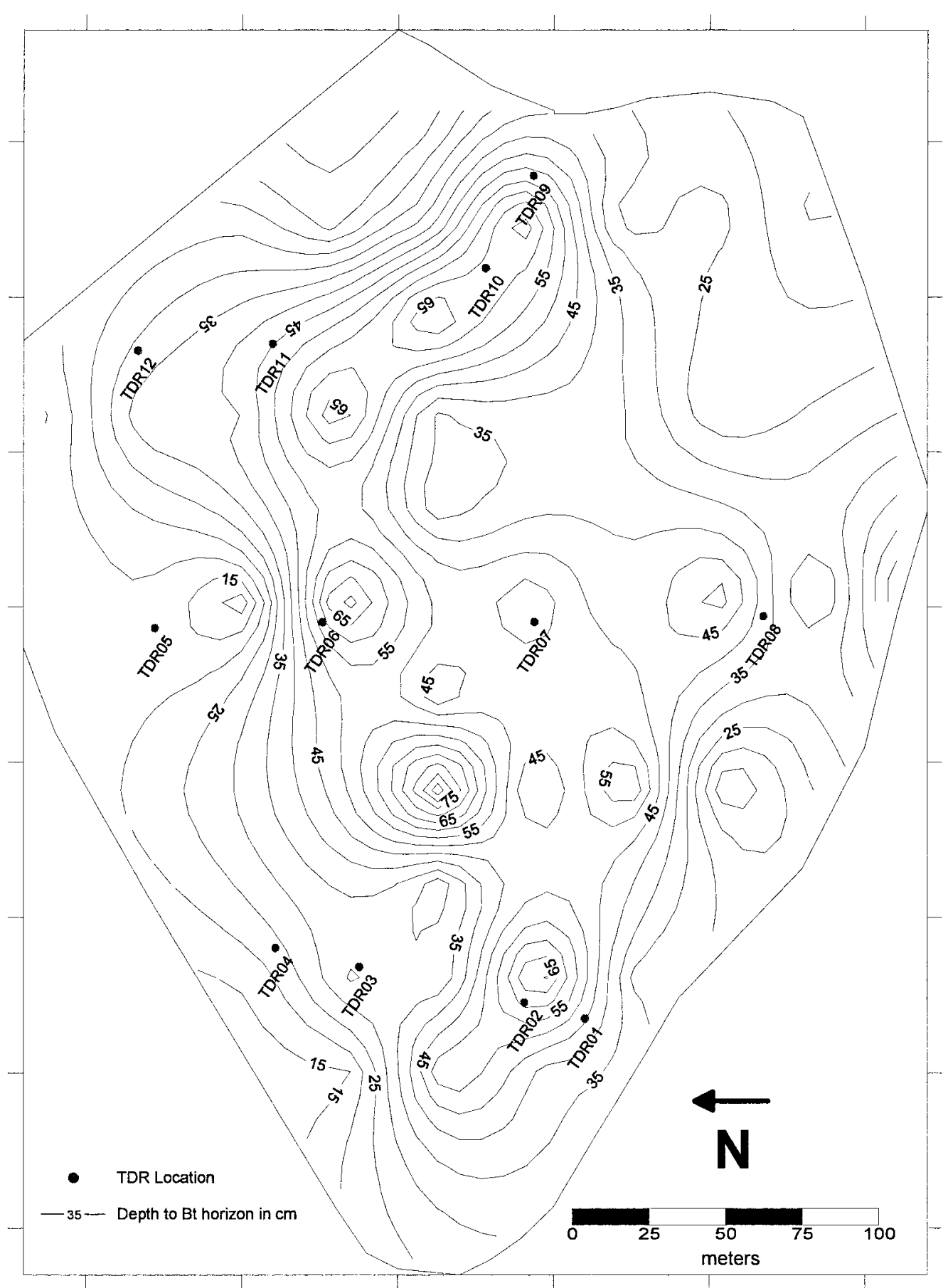

Fig. 3. Contour lines in centimeters of depth to top of the Bt horizon, and location of time domain reflectometry (TDR)-based soil water content measurement sites at W1.

$\mathrm{Bt}$ and $\mathrm{BC}$ horizons. The decrease follows an approximate exponential curve based on a regression of $K_{s}$ with depth to mid-horizons.

The catchment has been used in a rotational system for grazing cow-calf herds since 1960. Bermudagrass (Cynodon dactylon) provides the primary grazing while winter annuals such as rye (Secale cerale L.) seeded into the bermudagrass sod in the fall provide supplemental grazing. Grazing usually consists of 50 to 100 cows left in W1 to calve and care for their young in January and February. Hay is used to supplement the rye and other vegetation in the pasture. Cows and calves are then moved from the watershed and the pasture is allowed time to recover. A smaller number of cows and bulls are moved in and out of W1 during breeding season beginning early April until fall to graze bermudagrass production.

\section{Hydrologic Measurements}

Soil water was measured at 12 sites in W1 for $3 \mathrm{yr}$, beginning in February of 1998, with TDR-based method (MoisturePoint system model MP-917, ESI, Victoria, BC, Canada). The 1.2-m long TDR probe is designed to measure average volumetric soil water content in five segments of 0 to 15,15 to 30,30 to 60,60 to 90 , and 90 to $120 \mathrm{~cm}$. The probe consists of diode 
separated electronic circuitry for each segment, all encased in epoxy filler sandwiched between two flat stainless steel sidebars. One probe was vertically inserted in the ground at each site and measurements were made with a portable TDR meter.

The 12 sites were arranged in three blocks at the lower, mid and upper part of W1 with two probes on slopes (one probe each on opposite mid-slope location) and two probes at foot slopes (one each on opposite foot slopes) per block (Fig. 1). The TDR probes were located in selected areas to avoid microtopography such as depressions. Reading intervals varied but often readings were as frequent as two to three times a week for a total of 144 observations.

The TDR estimates of volumetric soil water content were tested by comparison with gravimetric derived soil water content (grams of water per grams of soil). Gravimetric and TDRbased soil water content measurements were made at the top four segments $(0-15,15-30,30-60$, and $60-90 \mathrm{~cm})$ at six of twelve TDR sites ( 24 in total) at the same time. Time domain reflectometry and gravimetric-based soil water content values were then isolated for the Ap horizon and compared. Similar comparison was made for soil water in the Bt horizon.

Rainfall was automatically recorded at 5-min intervals near the outlet of the W1 using a tipping bucket rain gauge (model TR525M, Texas Electronics, Inc., Dallas, TX) wired into a data logger (model CR10X, Campbell Scientific Inc., Logan, UT). Runoff was also automatically recorded at 5-min interval using the $1.14 \mathrm{~m}(3.75 \mathrm{ft})$ high 2 to 1 concrete broad-crested V-notch weir fitted with a Druck pressure transducer (Model PDCR 1830, Druck Inc., New Fairfield, CT) wired into the data logger to record flow depth.

Grass-referenced potential evapotranspiration (PET) was calculated with the Penman-Monteith method using the Reference Evapotranspiration Calculator V2.15 (Allen, 1994). Daily weather data for PET calculations were obtained from a Georgia Automated Network Weather Station (Hoogenboom, 1996) about $4.5 \mathrm{~km}$ west of W1.

\section{Statistical Methods}

If soil water at all sites behaved in a similar manner then relatively few sites would need to be monitored to describe soil water dynamics. To describe the differences in soil water fluctuation among the 12 TDR sites, we utilized a series of statistical methods: Mahalanobis distance (MD) (SAS, 1990), multidimensional scaling (MDS) (SAS, 1990; Schiffman et al., 1981), correlation analysis, and stepwise regression.

Mahalanobis distance is a well known statistical distance function introduced by P. C. Mahalanobis in 1936. It gives a measure of statistical distance (difference) between two points in space defined by two or more correlated variables based on a set of key characteristics. As such, it can be considered either as a similarity measure of an unknown sample set to a known one, or as dissimilarity measure between two random vectors of the same distribution. The smaller the MD, the more similar the variables based on the characteristic being examined. It is generally preferred over other distance functions because the MD technique relies on multivariate mean and covariance matrix in its operation. Euclidean distance, for instance, gives equal weight to each component of a vector. Mahalanobis distance assigns lower weights to those components that are strongly correlated with each other. Mahalanobis distance between a vector $\mathbf{x}$ and a set $\mathbf{S}$ of vectors is computed from the matrix equation:

$$
\mathrm{MD}^{2}=(\mathbf{x}-\mathbf{t})^{T} \mathbf{C}^{-1}(\mathbf{x}-\mathbf{t})
$$

where $\mathbf{x}$ is a vector quantity, $\mathbf{t}$ is the estimated multivariate location (usually the multivariate arithmetic mean or the centroid of the set of vectors), and $\mathbf{C}$ the estimated sample covariance matrix. The superscript $T$ denotes the transpose operator. In cases where there is no correlation and the variances are all similar, the MD is equivalent to Euclidean distance. Mahalanobis distance has been used extensively in classification, pattern recognition and other problems in ecology, GIS, medicine, pharmaceuticals, industry, and other disciplines (Cayuela, 2004; Clark et al., 1993; Farber and Kadmon, 2003; Knick and Dryer, 1997; Knick and Ratenberry, 1998; Legendre and Legendre, 1998; Mark and Tunnell, 1985; Ritchie et al., 2003; Seber, 1984).

In multidimensional scaling, a dimensional representation of objects is recreated given a set of distances (dissimilarities) between pairs of objects. A classic example is estimating the locations of a given number of American cities in two-dimensional space (i.e., a map) given only the distances between the city pairs. This is necessarily more complicated than the inverse problem of finding the distance between the cities given their coordinates (representation in space). Multidimensional scaling provides a visual representation of the pattern of proximities (i.e., similarities or distances) among a set of objects and a means of estimating the number of dimensions separating the objects. The goal is to detect the number of underlying dimensions needed to explain the observed similarities or dissimilarities. Subsequent analyses are used to search for relationships between the MDS dimensions and measured explanatory variables. The procedure is commonly used in marketing and social sciences.

To conduct the MDS statistical analysis, the soil water variation across all dates was first used to estimate MDs between sites as well as between sites by depth. Sites that exhibited similar variation in soil water across time would have small MDs, but sites that behaved differently would have much higher MDs. The MDs for all pairs of sample sites were placed in a triangular matrix representing all possible differences among the 12 TDR sites. We then utilized MDS to determine the number of statistical dimensions separating the behavior of the 12 TDR sites. If the relationships within the data were purely spatial one might expect that the MDS analysis would result in three dimensions that could then be correlated with latitude, longitude, and elevation. Although the 12 TDR sites are obviously arranged in three-dimensional space, the sites near each other may or may not behave in a similar manner than sites far from each other.

After determination of the number of dimensions separating the 12 sites with MDS, then we used correlation analysis and stepwise regression to identify the variables that best explained the MDS dimensions. Additional descriptive statistics were calculated as measures of central tendency and for comparisons of means.

\section{RESULTS AND DISCUSSION}

\section{Time Series of Average Soil Water Content}

Time series of average soil water content across the 12 sites (Fig. 4) and variation of soil water content between the driest and wettest sites across seasons (Fig. 5) indicate several features of the soil water dynamics at W1. Such dynamics might be common in many watersheds of the Southeastern Piedmont where Cecil soils are mapped, and perhaps other humid temperate regions with similar soils. Generally, volumetric soil water content was greatest in winter and least in summer. The wetter sites had particularly high soil water content below $15 \mathrm{~cm}$ (Fig. 5) in the winter, which might lead to 


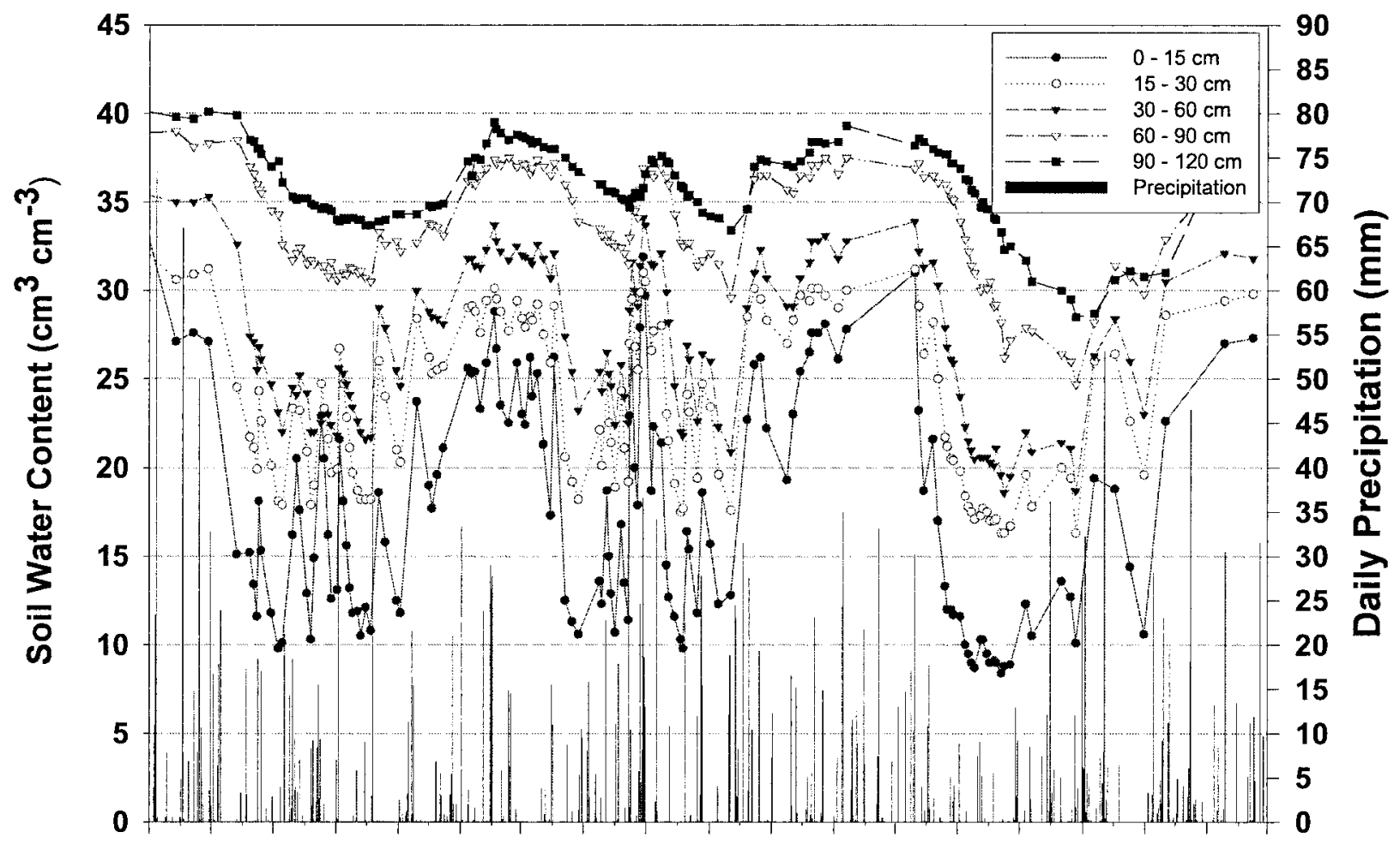

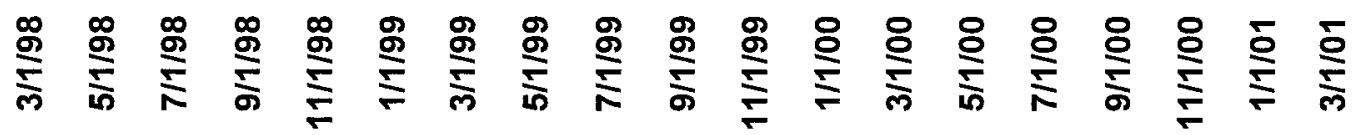

Fig. 4. Time series of average volumetric soil water content at W1 from 3 Mar. 1998 to 1 Mar. 2001.

disproportionate contribution to runoff from these sites. The soil water fluctuations in the relatively dry soils in summer reflect the periodic higher soil water content associated with the intense summer thunderstorms. Spring and fall were transitional periods. Soil water content of the profile was highly responsive to precipitation and evaporative demand. The variation was greatest in the surface soil $(0-15 \mathrm{~cm})$ and decreased with depth.

Mean monthly rainfall in millimeters was 108 for winter (median 93), 82 in spring (median 63), 88 in summer (median 69), and 76 in fall (median 74). Mean potential evapotranspiration (PET) in $\mathrm{mm} \mathrm{d}^{-1}$ was 1.6 for winter (median 1.5), 3.6 in spring (median 3.7), 4.8 in summer (median 5.0), and 2.6 in fall (median 2.6).

Average volumetric soil water content of the surface soil $(0-15 \mathrm{~cm})$ varied from approximately 8 to $12 \%$ in summer, except when influenced by intense summer storm, and approximately 22 to $30 \%$ in winter. Mean soil water content below $60 \mathrm{~cm}$ remained between 37 and $40 \%$ in the winter. In the summer of 1998 and 1999 it varied between 30 and $35 \%$, while in 2000 it remained below $30 \%$ for most of the summer. These soil water content variations between dry and wet conditions are consistent with characteristics of the Cecil soil reported in the literature and measured under laboratory conditions (Table 1; Bruce et al., 1983; Elkins et al., 1961; Holtan et al., 1966; Perkins, 1987). Textural differences (Fig. 2) account for the differences in soil water content at -33 and $-1500 \mathrm{kPa}$ between the Ap and other horizons.
The impact of climate on soil water was explained partly by the difference between total weekly precipitation and PET for 1998 to 2000 (Fig. 6). Only 6 wk in 1998, 5 in 1999, and 3 in 2000 from the 21 wk between April and August had surplus precipitation. The deficit was more pronounced in 2000 . The research period coincided with an agricultural drought lasting from mid-May 1998 through mid-November 2002. Historically this was one of the eight most prolonged (three or more years) droughts in Georgia since 1680 (Stooksbury, 2003). Depth to ground water at a monitoring well in the center of the W1 increased steadily from 3 to $7 \mathrm{~m}$ from August 1998 to February 2001.

Summer declines in soil water in the deeper profiles at W1 during 1998 to 2000 may partly be attributed to direct root water uptake to perhaps the $100-\mathrm{cm}$ depth. The drying of the lower profile was probably associated with both root water uptake and capillary movement of soil water to upper portions of the profile. Bermudagrass roots can reach $60-$ to $100-\mathrm{cm}$ depth in these soils as evidenced by observation of soil pits in an adjacent pasture. Perkins (1987) reported that bermudagrass roots extended to $150 \mathrm{~cm}$ in Cecil pedons in Georgia pastures.

Comparison between TDR and gravimetric-based soil water estimates for the $\mathrm{Ap}$ and $\mathrm{Bt}$ horizons are shown in Fig. 7. The data show good correlation between the two methods for each of the Ap and Bt horizons $\left(R^{2} 0.8\right.$ and $\mathrm{P}$ value $\left.<0.003\right)$. Based on this, and since the recorded soil water content variations between dry and wet conditions are consistent with characteristics 


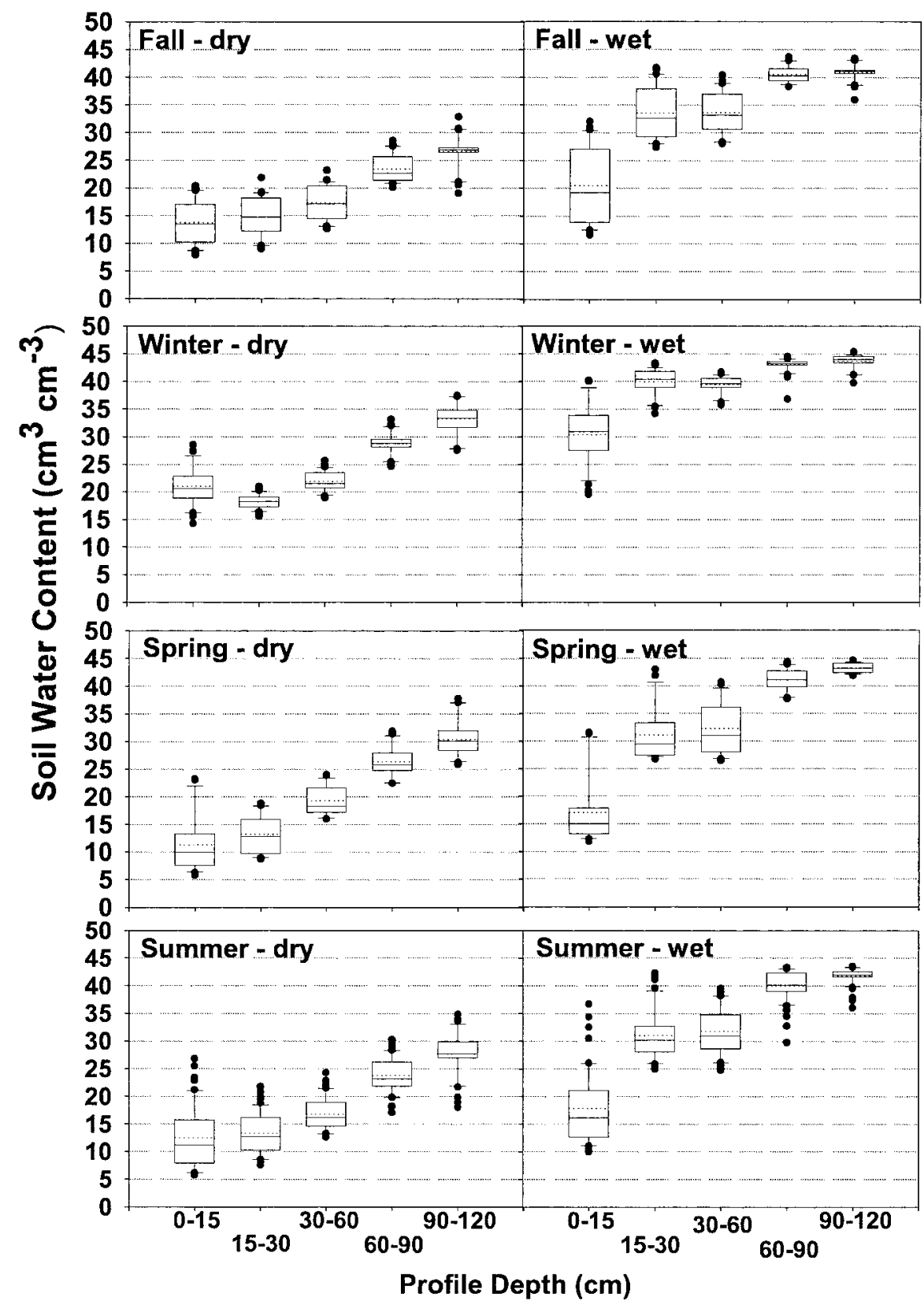

Fig. 5. Box plots showing distribution of average soil water content by depth and season for the three driest 'dry' and the three wettest 'wet' of the 12 soil water measurement sites. The dots indicate outliers beyond the 10th and 90th percentiles represented by the whiskers. Dashed and solid lines within the boxes indicate mean and median soil water content, respectively.

of the Cecil soil reported in the literature, the TDR measurements are considered adequate for the analysis presented here.

\section{Spatial Distribution of Soil Water Content}

After calculating the statistical differences between all pairs of sites, the MDS analysis indicated that the differences expressing the variation in soil water content were generated by a single dimension $(r=0.99$; Fig. 8$)$. The sites are distributed along a single scaled MDS axis and by depth varying along one axis only. The negative values indicate drier sites and positive values wetter sites. The zero-centimeter line of the depth axis (Fig. 8) shows the MDS values for the whole profile, the $-15-\mathrm{cm}$ depth line for the 0 - to $15-\mathrm{cm}$ depth, the $-30-\mathrm{cm}$ depth line for the 15- to 30-cm depth, and so on. The MDS analysis would have produced two or more dimensional graphs for each depth and/or for the whole profile if the soil water distribution had been influenced by more than one dimension. In that case, Fig. 8 would have been expanded to show multi-dimensional graphs for each soil depth and for the whole profile.

Some clustering into zones of similar soil water content is apparent and should be reflected in similar properties during the correlation analysis. Correlation analysis would be expected to identify a key variable associated with soil water variation since only one MDS dimension 
Table 1. Summary of soil water characteristics for Cecil soil.

\begin{tabular}{|c|c|c|c|c|c|c|c|c|}
\hline & \multicolumn{8}{|c|}{ Horizon } \\
\hline & \multicolumn{2}{|c|}{ Ap } & \multicolumn{2}{|c|}{ Bt1 } & \multicolumn{2}{|c|}{ Bt2 } & \multicolumn{2}{|c|}{ Bt3 } \\
\hline & & & & & & & & \\
\hline & 1500 & 33 & 1500 & 33 & 1500 & 33 & 1500 & 33 \\
\hline & & & & metric & conter & & & \\
\hline \multicolumn{9}{|l|}{ Statistics } \\
\hline Mean & 8.5 & 17.3 & 28.0 & 37.5 & 32.0 & 42.9 & 25.4 & 37.1 \\
\hline Median & 7.5 & 18.2 & 27.6 & 35.1 & 32.8 & 42.9 & 25.1 & 37.1 \\
\hline Standard deviation & 3.0 & 3.5 & 4.5 & 6.3 & 4.3 & 2.9 & 1.4 & 5.3 \\
\hline Minimum & 4.6 & 11.9 & 22.9 & 31.6 & 25.1 & 38.2 & 24.2 & 33.3 \\
\hline Maximum & 13.0 & 21.6 & 35.9 & 45.8 & 38.4 & 45.7 & 27.0 & 40.8 \\
\hline Sample number & 12 & 9 & 11 & 6 & 8 & 5 & 3 & 2 \\
\hline
\end{tabular}

was indicated. Over the whole profile, Sites 7,3 , and 2 are clustered together as the driest with 3 and 2 clustered more closely followed by the next dry cluster of Sites 6 and 10. On the other hand Sites 11, 9, and 12 are the wettest with 9 and 11 closely clustered, followed by the Sites 1, 4, and 5. Mean volumetric soil water content

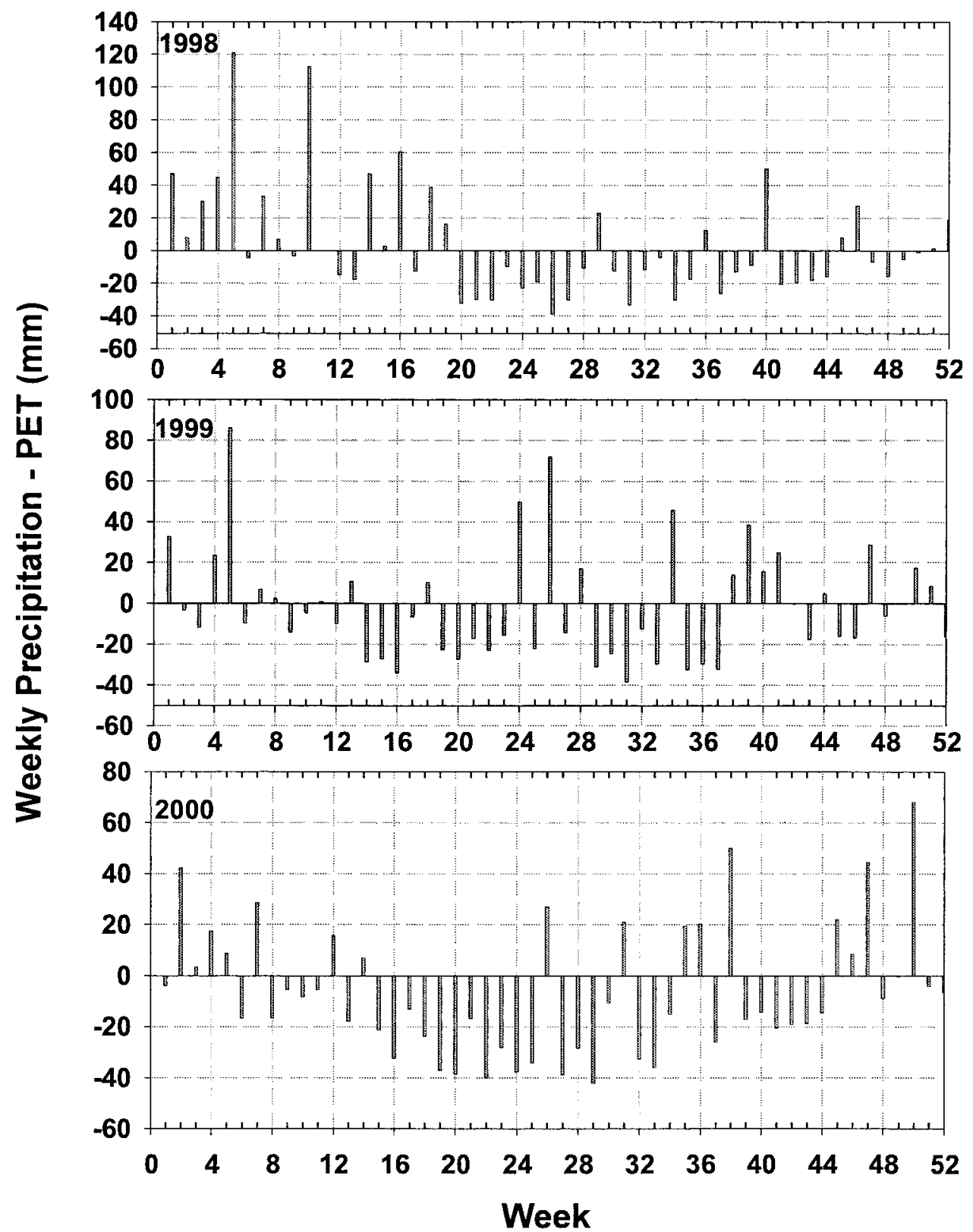

Fig. 6. Weekly precipitation less weekly potential evapotranspiration (PET) at W1 for 1998 to 2000. 

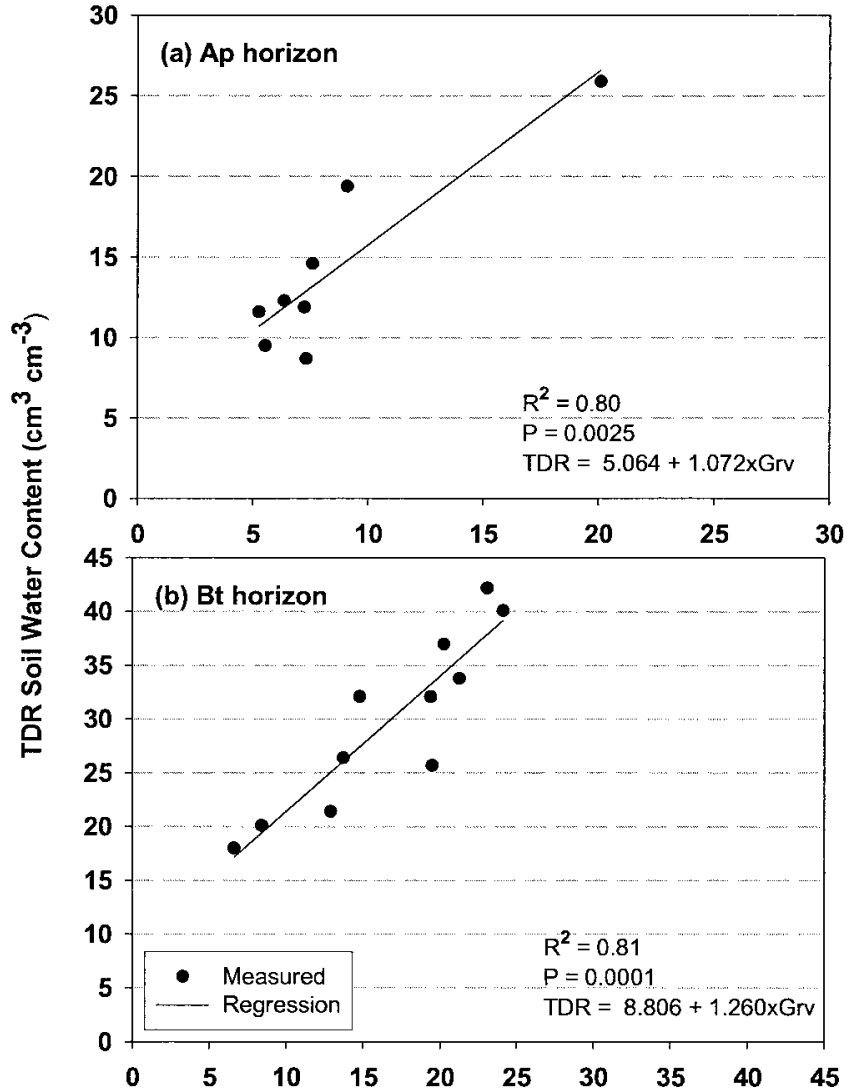

Gravimetric Soil Water Content $\left(\mathrm{g} \mathrm{g}^{-1}\right)$

Fig. 7. Comparison of time domain reflectometry (TDR) and gravimetric (Grv)-based soil water content for the Ap (a) and Bt (b) horizons at six of twelve TDR sites at W1. The legend in (b) applies to (a) also.

over 3 yr was $20.8 \%$ (Standard deviation 2.9) at Site 7 and $31.6 \%$ (Standard deviation 4.8 ) at Site 9. Generally, the mid slope positions $(1,4,5,9,12)$ were wetter than those at the foot slope $(2,3,6,7,10)$ with the exception of site 11 . The foot slope bounds the lower and flatter middle part of $\mathrm{W} 1$. The analysis by depth in the profile was similar with the exception of a few sites that alter their position within the MDS dimension. Site 7 was the driest or second driest down to the $60-$ to $90-\mathrm{cm}$ depth. Site 9 clustered with the wetter group down to the 30- to 60-cm depth. Site 8 had a lower (drier) MDS dimension but had a relatively greater (wetter) dimension when compared with the other dimensions in the 30- to 90-cm depth. Sites 4, 5, and 9 had relatively lower MDS dimensions in the deepest $(90-120 \mathrm{~cm})$ profile, as did Sites 6 and 10 .

It was somewhat surprising that the MDS analysis indicated that the statistical distances (Mahalanobis) of TDR sites were explained by a single dimension $(r=$ $0.99)$. Correlation analysis showed that the MDS dimension in the 15- to $30-\mathrm{cm}$ depth was associated with the depth to the Bt horizon $(r=0.69)$ and the depth of the whole Ap horizon in this section $(r=0.80)$. No other association was found, including for texture (sand, silt, or clay), over the five individual TDR measurement sections or the whole 0 - to $120-\mathrm{cm}$ profile. As indicated above, $K_{\mathrm{s}}$ decreases exponentially with depth and can be very low within the $\mathrm{Bt}$ horizon which can cause perched water to develop in horizons above. The $0-$ to $15-\mathrm{cm}$ section is a primary zone for meeting evaporative demands, which might explain why we found no association of MDS dimensional coefficients with depth to the top of the Bt as was found for the 15- to $30-\mathrm{cm}$ section.

\section{Restrictive Horizon and Soil Water Distribution}

Correlation between the physical distances estimated between the TDR sites and the statistical distances estimated as the MD was very poor $(r=0.18)$. This indicates that the observed variation in soil water is not related to position within the watershed in a simple way and particularly that sites close together do not necessarily behave similarly. In fact, the variation in soil water over time must be associated with a factor, or factors, that change rapidly throughout the watershed to prevent a correlation between physical distance and statistical distance. This fact coupled with the difficulty in explaining an MDS dimension with an " $r$ " of 0.99 appears to have a bearing on what Western et al. (1999b) observed. That is, that terrain indices (aspect, slope $\beta$, curvature, specific catchment area, specific upslope area a, $\tan (\beta)$, wetness index, $\ln [\mathrm{a} / \tan (\beta)]$, etc.) used to represent key hydrological processes controlling the spatial distribution of soil water in a simplified but realistic way have preformed well in some circumstances but poorly in many others. Our data suggests that the depth to Bt horizon in Cecil soils controls soil water in some horizons above in association with the coarser Ap horizon depth, and can perhaps be used as a terrain index. This should be of interest to many researchers across many disciplines.

The top of the Bt horizon appears deepest $(45-65 \mathrm{~cm}$ from the surface) at Sites 2, 6, 7, and 10. The MDS coefficients indicated that these sites were relatively dry. This was especially true in the upper profile. The Bt starts at $25 \mathrm{~cm}$ or less from the surface at Sites 4 and 5 , and $45 \mathrm{~cm}$ or less from the surface at Sites 9 and 12 . The upper soil profile at these sites was mapped by MDS as relatively greater (wetter; Fig. 8). Although Site 11 is at a foot slope, it is one of the relatively wetter sites also and the Bt starts at approximately $45 \mathrm{~cm}$ from the surface. The soil water in the upper profile of Site 8 clustered with the drier sites although the Bt starts between 35 and $40 \mathrm{~cm}$ from the surface (Fig. 2). Additional sampling might be required to explain this anomaly at these two sites ( 8 and 11). It might be that depth to and extent of the Bt horizon might differ from the interpreted values.

Textural and associated pore size, gravitational and capillary forces differences between the Bt and Ap horizons could partially explain the association of the depth to Bt horizon and the depth of the Ap horizon controlling soil water content in some horizons above the Bt. Water moves rapidly by gravity through the Ap (mean sand content about $67 \%$, Fig. 2). This water then perches on the $\mathrm{Bt}$, which has low hydraulic conductivity (mean clay content $40 \%$, Fig. 2). For the same volume of water 
Table 2. Details for runoff events at W1 from $10 / 5 / 1998$ to $2 / 15 / 2001$.

\begin{tabular}{|c|c|c|c|c|c|c|c|}
\hline \multirow[b]{2}{*}{ Soil water reading } & \multirow[b]{2}{*}{ Runoff occurrence } & \multirow[b]{2}{*}{ Rainfall amount } & \multicolumn{2}{|c|}{ Highest sustained rainfall } & \multicolumn{2}{|c|}{ Runoff $\uparrow$} & \multirow{2}{*}{$\begin{array}{c}\text { Rainfall previous } \\
7 \text { d }\end{array}$} \\
\hline & & & Intensity & Duration & Amount & Coef. & \\
\hline & & $\mathbf{m m}$ & $\mathbf{m m ~ h}^{-1}$ & h:min & mm & $\%$ & mm \\
\hline 10/5/1998 & $10 / 7 / 1998$ & 56.5 & 19.0 & $2: 10$ & 0.105 & 0.19 & 3.3 \\
\hline $12 / 15 / 1998$ & $1 / 2 / 1999$ & 33.4 & 6.8 & 3:40 & $\mathbf{0 . 0 5 2}$ & 0.17 & 2.5 \\
\hline 2/17/1999 & 2/19/1999 & 14.5 & 15.2 & $0: 45$ & $\mathbf{0 . 0 3 2}$ & 0.22 & 22.1 \\
\hline $6 / 15 / 1999$ & 6/16/1999 & 41.4 & 21.2 & $0: 25$ & 0.064 & 0.16 & 32.5 \\
\hline 6/25/1999 & 6/28/1999 & 36.6 & 60.2 & 0:30 & 3.446 & 9.42 & 43.9 \\
\hline $7 / 8 / 1999$ & 7/11/1999 & 34.2 & 25.9 & 1:00 & $\mathbf{0 . 0 5 2}$ & 0.15 & 18.0 \\
\hline $1 / 5 / 2000$ & $\mathbf{1} / 10 / 2000$ & 30.0 & 15.1 & 0:55 & 0.858 & 2.86 & 27.9 \\
\hline $\mathbf{1} / \mathbf{1 8} / \mathbf{2 0 0 1}$ & $1 / 19 / 2001$ & 30.5 & 19.3 & 0:50 & 0.458 & 1.50 & 10.7 \\
\hline $2 / 15 / 2001$ & $2 / 22 / 2001$ & 31.5 & 9.6 & $2: 30$ & 0.064 & 0.20 & 16.8 \\
\hline
\end{tabular}

$\dagger 1 \mathrm{~mm}$ is equivalent to approximately $77700 \mathrm{~L}$ of runoff at $\mathrm{W1}$; runoff coefficient (coef.) is the runoff amount as percent of rainfall.

that has infiltrated, the upper landscape positions would show higher water content than the lower positions because of reduced total pore volume to distribute and hold the infiltrated water as a result of the sandy soil of reduced depth above the Bt.

\section{Influence of Soil Water on Runoff Generation}

Despite the drought, several runoff events were recorded beginning in June of 1998 when an automated rainfall-runoff measurement system was put in place at W1. On-going soil water content measurements occurred a few days before nine runoff events (Table 2). The amount of runoff was generally small, but we investigated how soil water content might have influenced runoff generation. For each site, the soil water content measurements preceding each runoff event were compiled. The sites were then ranked according to the mean soil water content before runoff. Separate rankings were created for the $0-$ to $15-\mathrm{cm}$ and the $15-$ to $30-\mathrm{cm}$ depths (Fig. 9).

There were significant differences in soil water content among many sites before runoff events (note letters above the box plots indicating statistical significance in Fig. 9). Differences were greatest in the $15-$ to $30-\mathrm{cm}$ profile with sites at mid-slope and bottom-slope positions clustering into wetter and drier zones, respectively. This variation would be relevant to spatial variation in runoff generation that would be expected to begin in the wetter zones (saturation excess). Such wet zones on

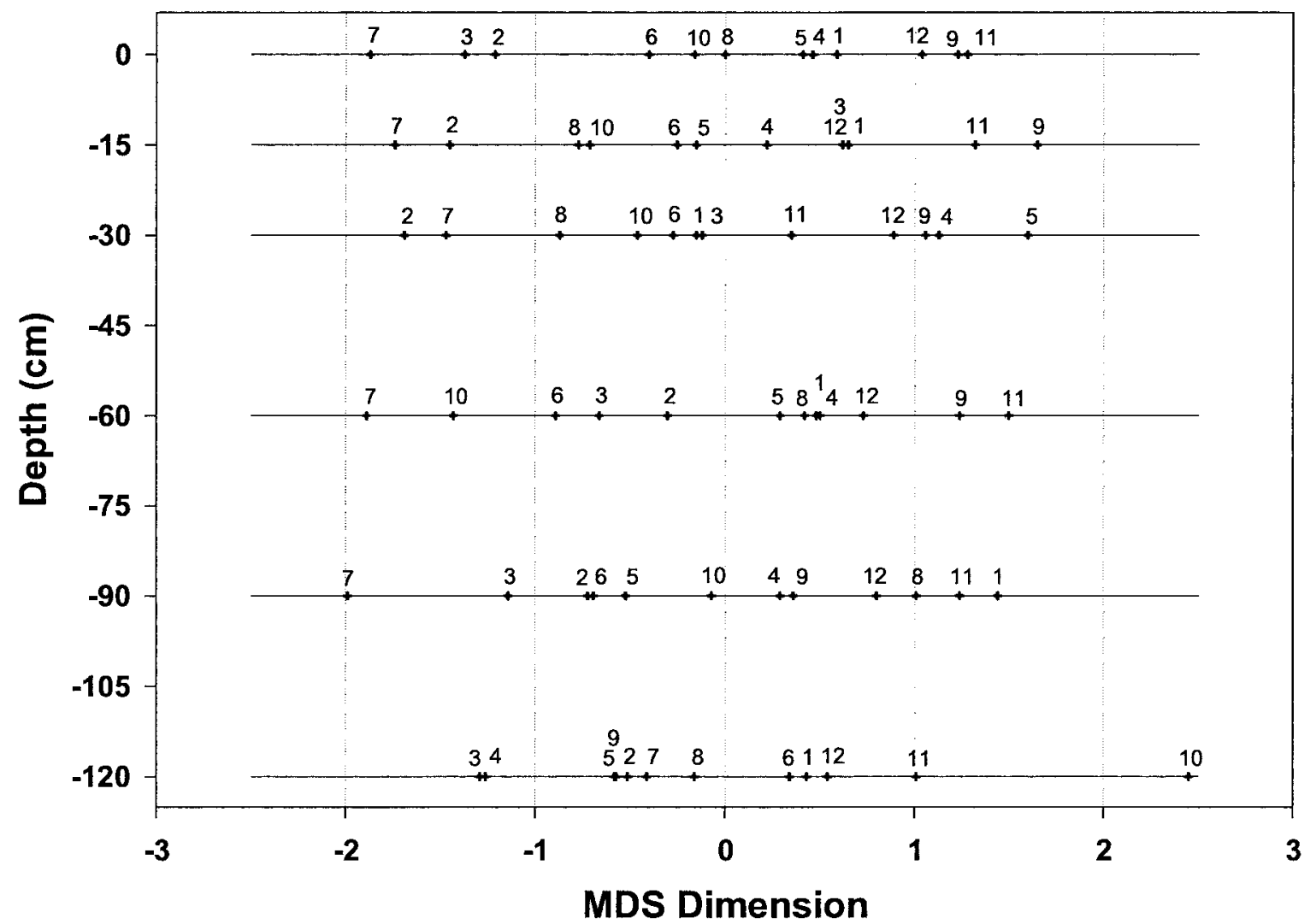

Fig. 8. Multidimentional scaling (MDS) dimensions for the 12 soil water measurement sites. Dimensions at the zero depth line of the depth axis are for the whole profile, those at the $-15-\mathrm{cm}$ depth line for the 0 - to $15-\mathrm{cm}$ depth, and those at the $-30-\mathrm{cm}$ depth line for the $15-$ to $30-\mathrm{cm}$ depth, and so on. 

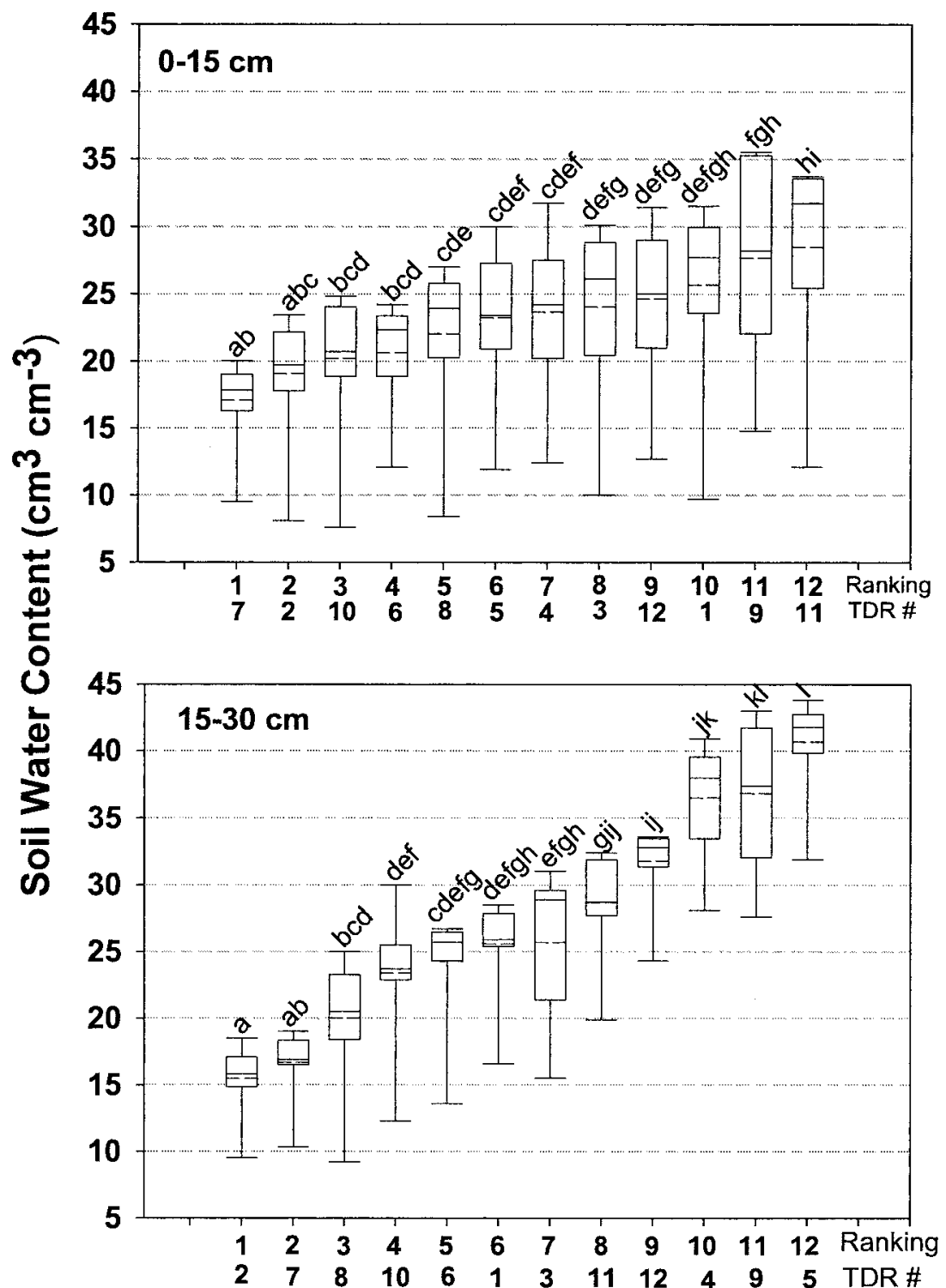

\section{Soil water ranking from 1 dry to 12 wet and equivalent TDR site number}

Fig. 9. Box plots showing distribution of soil water content in the 0- to 15- and 15- to 30-cm depths before runoff events at the 12 TDR-sites, with sites ranked from 1, dry, to 12, wet based on mean soil water content. Dashed and solid lines within the boxes indicate mean and median soil water content, respectively.

slopes could be source of water to low lying areas by interflow (Bonell, 1998; McGlynn et al., 2002). The lower extremes in Fig. 9 are a result of soil water having been low during the first runoff event. Runoff would have been generated by a combination of mechanisms during that event. For that event, the highest sustained rainfall intensity of $19 \mathrm{~mm} \mathrm{~h}^{-1}$ was similar to the intensities for some of the other rainfall events but it had the longest duration of $3 \mathrm{~h}$ and $40 \mathrm{~min}$, which would have led to the eventual saturation of surface soils (Table 2). Except for the one event showing a high 30-min long $60.2 \mathrm{~mm} \mathrm{~h}^{-1}$ intensity, the intense rainfall rates for other events were close to or below $K_{\mathrm{s}}$ values measured by Bruce et al. (1983) at the surface.
To see the distribution of dry and wet soil water frequency classes among the TDR sites before the nine runoff events, each site was ranked from 1 (driest) to 12 (wettest) for each event and for each depth. The three driest $(1,2,3)$ rankings were labeled 'dry' and the three wettest $(10,11,12)$ rankings were labeled 'wet' for each event. The 'dry' or 'wet' count (frequency) of the top $30-\mathrm{cm}$ section from the nine events showed the following distribution. Sites 2, 7, and 6 occurred as 'dry' 18,16 , and 6 times, respectively; this out of a potential occurrence of 27 each $(9 \times 3)$. Sites 5, 9, 12 occurred as 'wet' 14, 14, and 6 times, respectively.

The sites that had already been shown to be the driest still maintained that status $(2,7,6)$. This zone is the flatter 
middle part of the watershed approximately bounded by the foot slopes. The wetter sites remained so $(9,5,12)$. This zone occupies the north and east slopes where the Pacolet soil occurs. As indicated, the Pacolet is a shallow soil compared with the Cecil, and the Bt horizon lies closer to the surface than in the Cecil. It is likely that the shallow soils occupying the mid to upper positions inW1 are primary sources of runoff generation for most runoff events. Radcliffe et al. (1990) found that infiltration rates were considerably higher in a Cecil than an adjacent Pacolet soil because the horizon controlling infiltration, Bt1, occurred much deeper in the Cecil than the Pacolet. Much of the literature on the concept of variable sources of runoff generation addresses lowlying zones prone to saturation from surface and subsurface flow (i.e., O'Loughlin, 1981; Bernier 1985; Lyon et al. (2004)). This research shows that the concept must be modified for areas in upper parts of landscapes underlain by restrictive horizons. This is especially important in landscapes where such soils are common both in the USA and other parts of the world.

Over $86 \%$ of the Southern Piedmont is classified as eroded by the USDA Natural Resource Conservation Service, and about $38 \%$ of the land is in Class IV and VI best suited for pastures and forests (Southern Piedmont Conservation Research Center, 1997). Trimble (1974) estimated an average of $18 \mathrm{~cm}$ of the Piedmont surface soil to have been eroded and lost due to generation of intensive row-crop agriculture. Some areas have lost over $30 \mathrm{~cm}$ of the surface soil. Erosion on Southern Piedmont landscapes causes the restrictive lower Bt horizon to be closer to or at the surface, which could lead to more runoff generation at these sites. The relationship of restrictive soil horizons in other eroded landscapes may also be a key to understanding rainfall-runoff relationships.

\section{CONCLUSIONS}

This research has identified some key issues related to spatial and temporal variation in soil water content of a typical Southern Piedmont landscape under pasture. The influence of rainfall and ET interact with the horizontal and vertical distribution of the Bt soil horizon. Winters are periods of high soil water content, while summers are periods when soil water content is least, except when influenced by typically intense storms.

Mid and upper slope areas are generally wetter than low-lying areas because of the perching effect of the $\mathrm{Bt}$ horizon, which is closer to the surface in the upper slopes coupled with reduced soil (pore) volume to distribute and hold infiltration water in the overlying coarser soil. The low-lying areas have deeper surface soils and a Bt horizon that lies relatively deeper than in the upper slopes. Even if there was interflow, it would have required considerably more water movement into these low-lying areas to make a difference in soil water content. These observations were influenced by the coincidental period of drought during the research. Similar data are needed during periods of abundant precipitation to determine if the observed soil water dynamics would differ in the two landscape positions during precipitation surplus.

This research indicates that it is crucial to know the spatial distribution of the Bt horizon to better understand the soil water dynamics of landscapes occupied by the Cecil and related soils, which are mapped over large areas in Southeastern USA. Similar landscapes are expected to occur beyond the Southern Piedmont. Upper parts of landscapes with convex slopes and underlain by Bt horizons close to the surface can contribute runoff to low-lying areas that are often perceived to be the primary variable source areas for runoff generation. The observed soil water dynamics at W1 has important implications for modeling the soil water dynamics and runoff processes. Mapping and integrating the Bt horizon into a GIS framework may have potential use in predicting soil water and runoff. The finding also has implications with respect to precision or site-specific agriculture for plant and soil scientists.

\section{ACKNOWLEDGMENTS}

Authors appreciate help by Stephen Norris in collecting and organizing the data, Curt Bokey in collecting data, and Tony Dillard and Dr. Dwight Seman in analysis of the data. Dr. Russ Bruce's (Soil Scientist, USDA-ARS, Watkinsville, GARetired) past work describing the horizon and textural distribution of the soil at W1 is also appreciated. Authors are grateful to anonymous reviewers for helping improve the manuscript. The mention of trade or manufacturer names is made for information only and does not imply an endorsement, recommendation, or exclusion by USDA Agricultural Research Service.

\section{REFERENCES}

Allen, R.G. 1994. Reference evapotranspiration calculator V2.15. Utah State University Foundation, Utah State University.

Bernier, P.Y. 1985. Variable source areas and storm-flow generation: An update of the concept and a simulation effort. J. Hydrol. (Amsterdam) 79:195-213.

Beven, K.J. 1989. Changing ideas in hydrology - The case of physically based models. J. Hydrol. (Amsterdam) 105:157-172.

Bonell, M. 1998. Selected challenges in runoff generation research in forests from the hillslope to headwater drainage basin scale. J. Am. Water Works Assoc. 34(4):765-786.

Bruce, R.R., J.H. Dane, V.L. Quisenberry, N.L. Powel, and A.W. Thomas. 1983. Physical characterization of soils in the southern region: Cecil. Southern Coop. Series Bull. No. 267. Georgia Agric. Exp. Stn. Athens.

Cayuela, L. 2004. 2004. Habitat evaluation for the Iberian wolf Canis lupus in Picos de Europa National Park, Spain. Appl. Geography 24:199-215.

Clark, J.D., J.E. Dunn, and K.G. Smith. 1993. A multivariate model of female black bear habitat for a geographic information system. J. Wildl. Manage. 57:519-526.

Elkins, C.B., Jr., G.G. Williams, and F.T. Ritchie, Jr. 1961. Soil moisture characteristics of some Southern Piedmont soils. Agricultural Research Service ARS 41-54. USDA, Washington, DC.

Farber, O., and R. Kadmon. 2003. Assessment of alternative approaches for bioclimatic modeling with special emphasis on the Mahalanobis distance. Ecol. Modell. 160:115-130.

Grayson, R.B., I.D. Morre, and T.A. McMahon. 1992. Physically based hydrologic modeling 2: Is the concept realistic? Water Resour. Res. 28:2639-2658.

Holtan, H.N., C.B. England, G.P. Lawless, and G.A. Schumaker. 1966. Moisture-tension data for selected soils on ARS experimental watersheds. Research Rep. No. 389. Soil and Water Conservation Research Division, Agric. Res. Serv., USDA, Washington, DC.

Hoogenboom, G. 1996. The Georgia automated environmental moni- 
toring network. p. 343-346. In Proceedings of the 22nd Conference on Agricultural and Forest Meteorology and the 12th Conference on Biometeorology and Aerobiology. American Meteorology Society, Boston, MA

Knick, S.T., and D.L. Dryer. 1997. Distribution of black-tailed jackrabbit habitat determined by GIS in southwestern Idaho. J. Wildl. Manage. 61:75-85.

Knick, S.T., and J.T. Ratenberry. 1998. Limitations of mapping habitat use areas in changing landscapes using the Mahalanobis distance. J. Agric. Biol. Environ. Stat. 3:311-322.

Legendre, P., and L. Legendre. 1998. Numerical ecology, second ed., Elsevier, Amsterdam.

Loague, K. 1992. Soil water content at R-5. Part 1. Spatial and temporal variability. J. Hydrol. (Amsterdam) 139:233-251.

Lyon, S.W., M.T. Walter, P. Gerard-Marchant, and T.M. Steenhuis. 2004. Using a topographic index to distribute variable source area runoff predicted with the SCS curve-number equation. Hydrol. Proc. 18:2757-2771.

Mark, H.L., and D. Tunnell. 1985. Qualitative near infrared reflectance analysis using Mahalanobis distances. Anal. Chem. 57:1449-1456.

McGlynn, B.L., J.J. McDonnell, and D.D. Brammer. 2002. A review of the evolving perceptual model of hillslope flow paths at the Miamai catchments. J. Hydrol. (NZ) 257:1-26.

NRC. 1999. New strategies for America's watersheds. National Ressearch Council, National Academy Press, Washington, DC.

O'Loughlin, E.M. 1981. Saturation regions in catchments and their relations to soil and topographic properties. J. Hydrol. (Amsterdam) 53:229-246.

O'Loughlin, E.M. 1986. Prediction of surface saturation zones in natural catchments by topographic analysis. Water Resour. Res. 22: 794-804.

Perkins, H.F. 1987. Characterization data for selected Georgia soils. Georgia Agric. Exp. Stn. University of Georgia, Athens, GA

Radcliffe, D.E., and L.T. West. 2000. MLRA 136: Southern Piedmont. Southern Cooperative Series Bulletin \#395. University of Georgia, Athens, GA

Radcliffe, D.E., L.T. West, G.O. Ware, and R.R. Bruce. 1990. Infiltration in adjacent Cecil and Pacolet soils. Soil Sci. Soc. Am. J. 54:1739-1743.
Ritchie, G.E., H. Mark, and E.W. Ciurczal. 2003. Evaluation of the conformity index and the Mahalanobis distance as a tool for process analysis: A technical note. AAPS PharmSciTech 4(2), Article 24. Available online at http://www.aapspharmscitech.org/articles/pt0402/ pt040224/pt040224.pdf (verified 12 Sept. 2005).

Robock, A., K.Y. Vinnikov, G. Srinivasan, J.K. Entin, S.E. Hollinger, N.A. Speranskaya, S. Liu, and A. Namkjai. 2000. The global soil moisture bank. Bull. Am. Meteorol. Soc. 81:1281-1299.

SAS. 1990. SAS/STAT user's guide. Ver. 6. 4th ed. SAS Institute Inc., Cary, NC.

Schiffman, S.S., M.L. Reynolds, and F.W. Young. 1981. Introduction to multidimentional scaling: Theory, methods, and applications. Academic Press, New York.

Seber, G.A.F. 1984. Multivariate observations. John Wiley \& Sons, New York.

Southern Piedmont Conservation Research Center. 1997. Open house and dedication. USDA-ARS, Southern Piedmont Conservation Research Center. Watkinsville, GA.

Stooksbury, D.E. 2003. Historical droughts in Georgia and drought assessment and management. p. 194-197. In Kathryn J. Hatcher (ed.) Proceedings of the 2003 Georgia Water Conference, Institute of Ecology, The University of Georgia, Athens.

Trimble, S.W. 1974. Man-induced soil erosion on the Southern Piedmont, 1700-1970. Soil Conservation Society of America, Ankeny, IA.

Weiler, M., and J. McDonnell. 2004. Virtual experiments: A new approach for improving process conceptualization in hillslope hydrology. J. Hydrol. (Amsterdam) 285:3-18.

Western, A.W., G. Bl-schl, and R.B. Grayson. 1998. Geostatistical characterization of soil moisture patterns in the Tarrawarra catchment. J. Hydrol. (Amsterdam) 205:20-37.

Western, A.W., R.B. Grayson, and T.R. Green. 1999a. The Tarrawarra project: High resolution spatial measurement, modeling and analysis of soil moisture, and hydrologic response. Hydrol. Processes 13:633-652.

Western, A.W., R.B. Grayson, G. Bl-schl, G.R. Willgoose, and T.A. McMahon. 1999b. Observed spatial organization of soil moisture and its relation to terrain indices. Hydrol. Processes 35:797-810. 